\title{
Fabrication and Application of Bismuth-Film Modified Glassy Carbon Electrode as sensor for Highly Sensitive Determination of Cetirizine Dihydrochloride in Pharmaceutical Products and Water Samples
}

\author{
Eman A. Al-Harbi \\ Department of Chemistry, Faculty of Science, Taibah University, Al-Madinah Al-Minawara 42353, \\ Kingdom of Saudi Arabia \\ E-mail: eahharbi@ taibahu.edu.sa
}

Received: 20 June 2021 / Accepted: 9 August 2021 / Published: 10 September 2021

The considerable necessity to detect and analyze cetirizine dihydrochloride (CTZ) residues has motivated the development of cost-effective and high-performance sensing probes. A highly sensitive, square wave anodic stripping voltametric (SW-ASV) methodology has been employed in correspondence with a bismuth-film platted glassy carbon electrode (BiF/GCE) for the establishment of the CTZ drug at trace levels in an aqueous media of $\mathrm{pH}$ 8.0. The nature and mechanism of the electrode reactions have been ascribed at $\mathrm{BiF} / \mathrm{GCE}$ for the square wave and cyclic voltammetry techniques. Under the optimized parameters and at $\mathrm{pH}$ 8.0, a well-defined square wave (SW) anodic stripping peak at + $0.48 \mathrm{~V}$ versus $\mathrm{Ag} / \mathrm{AgCl}$ was detected. The plot of the anodic current versus known concentrations of CTZ was linear in the range of $\left[5.0 \times 10^{-9}-1.2 \times 10^{-6} \mathrm{~mol} \mathrm{~L}^{-1}\right](\mathrm{R} 2=0.999)$ with limits of detection (LOD) and calculation (LOQ) of $1.5 \times 10^{-9}$ and $5.0 \times 10^{-9} \mathrm{~mol} \mathrm{~L}^{-1}$, respectively. The acquired SW-ASV technique was successfully employed for the determination of nano concentrations of CTZ in pharmaceutical preparations and water samples on BiF/GCE. These method provides a good correlation with the data obtained for the deduction of CTZ in numerous matrices through the spectrophotometric approach.

Keywords: Stripping voltammetry; Cetirizine dihydrochloride; Bi film modified electrode; Glassy carbon electrode; Pharmaceutical preparations; Environmental water.

\section{$\underline{\text { FULL TEXT }}$}

(C) 2021 The Authors. Published by ESG (www.electrochemsci.org). This article is an open access article distributed under the terms and conditions of the Creative Commons Attribution license (http://creativecommons.org/licenses/by/4.0/). 